\title{
Erratum to: A multiscale overlapped coupling formulation for large-deformation strain localization
}

\author{
WaiChing Sun · Alejandro Mota
}

Published online: 17 June 2014

(C) Springer-Verlag Berlin Heidelberg 2014

\section{Erratum to: Comput Mech}

\section{DOI 10.1007/s00466-014-1034-0}

The wrong captions for Fig. 11a, b have been published due to a production error. The correct caption should be:

Fig. 11 Singular bar. Load-displacement curves from $H^{1}$ coupling with a local damage model in the fine mesh and $\mathbf{b}$ nonlocal damage model in the fine mesh

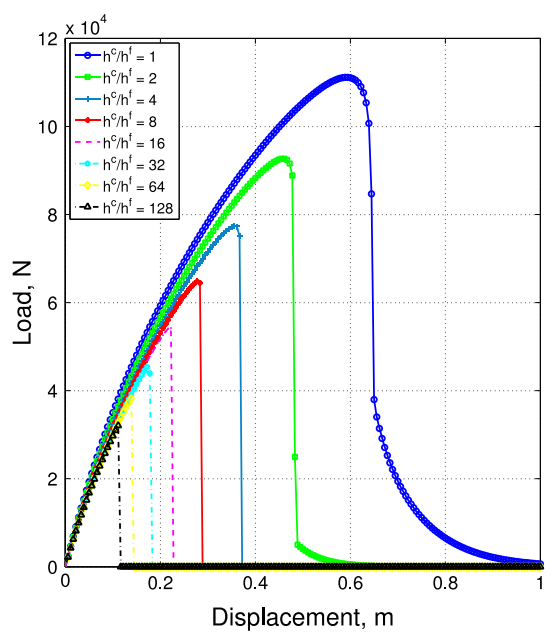

(a) Local-to-local coupling

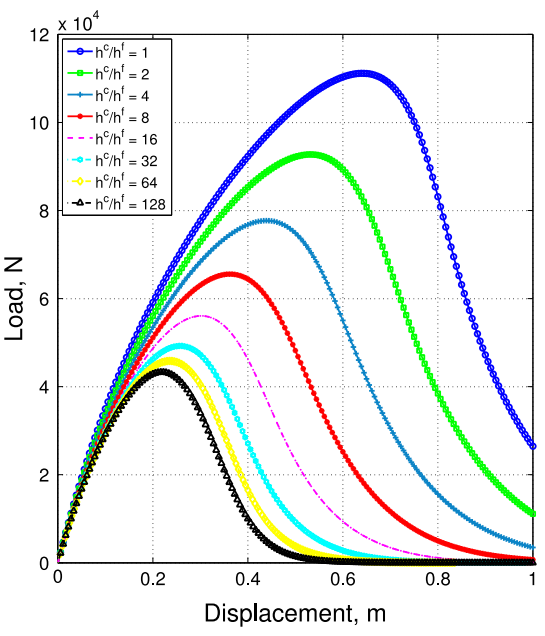

(b) Nonlocal-to-local coupling

The online version of the original article can be found under doi:10.1007/s00466-014-1034-0.

W. Sun $(\bowtie)$

Department of Civil Engineering and Engineering

Mechanics, Columbia University in the City of New York,

New York, NY 10027, USA

e-mail:ws2414@columbia.edu

\section{A. Mota}

Mechanics of Materials Department, Sandia National Laboratories,

Livermore, CA 94550, USA 